\title{
Research on the Influencing Factors of Purchasing Internet Financial Wealth Management Products Based on AHP
}

\author{
Xueying Feng* \\ Business School, University of Exeter, Exeter, United Kingdom \\ *Corresponding author: Xueying Feng, xf239@exeter.ac.uk
}

\begin{abstract}
Internet financial wealth management product (IFWMP) has recently been one of the most gained popularity. There are limited quantitative research on IFWMP which can help customers to choose products based on the significance of each factor. In this paper, a multi-criteria decision-making model for IFWMP was developed, namely the analytic hierarchy process (AHP) which is commonly used to make decisions for unstructured problems through quantifying weights of each criterion. This paper investigated ten influential factors relevant to the purchase of IFWMP and analyzed the frequency of collected response to show the significance of the factors. Based on the quantified weights, the results of the research indicated that compatibility, product liquidity, perceived ease of use, and perceived usefulness affected investors purchasing behaviors and that every investor should pay great attention to.
\end{abstract}

Keywords: Internet financial wealth management products (IFWMP); Analytic hierarchy process (AHP); Compatibility; Product liquidity; Purchasing behaviors

Publication date: August 2021; Online publication: August 30, 2021

\section{Introduction}

In recent years, China has experienced a booming economic development. The gross domestic product (GDP) in China has increased considerably from 6.44 trillion yuan in 2014 to 9.9 trillion yuan in 2019 with an average annual growth of $10.7 \%$. In the meantime, the per capita disposable income of Chinese residents has gradually risen from approximately 22,000 yuan to 30,000 yuan ${ }^{[1]}$. Currently, with the gradual increase of the per capita disposable income, their financial demand is developing. According to the report from China Merchants Bank (CMBC) and Bain Capital, the number of Chinese high-net-worth individuals with investable assets of more than 10 million yuan had reached 1.97 million in 2018. The total amount of investable assets held by individuals in China had reached 190 trillion yuan during the same period of time

${ }^{[2]}$. It is possible for more people to pay more attention to financial products so as to achieve an increase in capital value.

Traditional financial products in China rely on the banking industry. Therefore, people were likely to select savings as the main means in the past under the situation of asymmetric information as well as the limitation of high investment threshold of conventional financial institutions. Now, it is a new period of information technology where the rapid development of the internet had led to the innovation of the financial industry in this internet age. Internet finance, which is an innovative financial mode that adopts the internet and mobile communication technologies to realize financing, payment, investment, and information intermediary services, emerged at a proper time and situation ${ }^{[3]}$.

Representative internet financial products such as third payment, peer-to-peer (P2P), and balance 
treasure have some impacts and influences on traditional bank businesses. Among the internet financial products, the internet financial wealth management products (IFWMPs), such as Yu'ebao and Tencent financial management products, have developed rapidly. The main characteristics of IFWMPs include low investment threshold, more types, short period of time, and convenient purchasing form, which would satisfy the financial services requirements and become the main investment choice for ordinary consumers. For example, the number of users and the capital scale of Yu'ebao had reached 641 million and 1.09 trillion yuan, respectively at the end of $2019^{[4]}$. Facing all types of complex IFWMPs, it is difficult for consumers to make reasonable decisions and select satisfactory products. Therefore, it is necessary to explore the influencing factors of IFWMPs so as to help consumers evaluate different IFWMPs.

\section{Literature review}

The past few decades had witnessed a plethora of studies about the purchase of internet financial products. Some literatures involved the technology acceptance model (TAM) as follows: Xia and Du (2014) established the intentions and attitudes toward purchasing IFWMP based on the technology acceptance model where they chose four dimensions including product innovation, attitude, purchasing cost, and government regulations to evaluate the relationship with purchase intention ${ }^{[5]}$. Wang (2016) combined the investors investment behavior theory (IIBT) with TAM to measure seven variables which include the common variables on TAM (perceived usefulness, perceived ease of use) and the additional variables based on IIBT (perceived risk, financial starting point, expected return, product liquidity, product awareness). He used the method of structural equation model (SEM) to analyze and examine the sample data ${ }^{[6]}$. Qiu and other researchers (2015) adopted the theory of planned behavior (TPB) and TAM, added the self-efficacy and social influences factors, as well as analyzed Yu'ebao as an example. They examined the structural equation model of IFWMP through the method of partial least squares (PLS). Their study showed that selfefficacy, perceived usefulness, and perceived ease of use play key roles as influencing factors in the usage of IFWMP ${ }^{[7]}$.

Some relevant research involved other methods such as unified theory of acceptance and use of technology, radial basis function (RBF) neural network, diffusion of innovation theory, risk theory, etc. The representative literatures are listed as follows: A study in 2014 had adopted the unified theory of acceptance and use of technology (UTAUT) with a perceived risk factor to analyze customers' behavioral intention of internet banking. It illustrated three factors from the UTAUT model which were performance expectancy, effort expectancy, and social influence in addition to perceived risk as the most crucial factors of customers' intention to use internet banking ${ }^{[8]}$. Liu and other researchers (2015) employed the RBF neural network to simulate the process of purchasing IFWMP. Through the empirical analysis of 12 selected variables, it demonstrated that the speed of realization, rate of return, convenience of payment, and access were the key factors in the purchasing intention of IFWMP ${ }^{[9]}$. Zhao and other researchers (2017) selected three factors which included perceived risk, personal innovation cognition, and brand awareness on the basis of diffusion of innovation theory and risk theory. By using the structural equation model, they concluded that in the process of purchasing internet financial products, personal innovation directly affected consumers' behavior while the brand awareness and perceived risk had a positive and negative impact on consumers' purchase intention, respectively ${ }^{[10]}$. Then, based on the grounded theory and utility maximization, Zhao and other researchers (2017) introduced and analyzed the selection factors of internet financial products by using a qualitative research and the nested logit model. They believed that user experience, product reputation, and risk diversification have significant impact on product selection ${ }^{\text {[11] }}$. Based on the social cognitive theory (SCT), $\mathrm{Xu}$ and $\mathrm{Lu}$ (2017) adopted five potential factors: internet atmosphere, computer self-efficacy, risk control cognition, communication, and trading trust. Their research results showed that three factors, which were computer self-efficacy, risk control cognition, and trading trust, directly affected consumers' purchase intention and behavior while internet atmosphere and communication had obvious indirect effects ${ }^{[12]}$. Zhang and other researchers (2020) used the Pythagorean fuzzy double normalization-based multiple aggregation (PF-DNMA) method to discuss the correlation 
between factors affecting consumers' purchase of financial products by comparing the Pythagorean Fuzzy TOPSIS (technique for order preference by similarity to ideal solution) method with VIKOR (VIseKriterijumska Optimizacija I Kompromisno Resenje, in Serbian, meaning multi-attribute optimization and compromise solution) method ${ }^{[13]}$. In 2020, a study targeted the consumers' barriers in the usage of internet banking in Karachi, Pakistan with innovation factors rather than normal productive elements used in TAM and TPB. It adopted five factors which were image barrier, value barrier, risk barrier, tradition barrier, and gender. By using several means of analysis, the study suggested that value, risk, and image barriers influenced the usage of internet banking significantly and positively ${ }^{[14]}$.

Based on the aforementioned, many foreign researchers focused on the exploration of the adoption intention and behavior of e-finance, internet banking, and mobile payment. The research on IFWMP is limited although IFWMP is also a typical form of an internet financial product. In addition, a few quantitative studies on purchasing intention had been conducted in regard to IFWMP. Therefore, the contribution of this work lies in identifying the main influencing factors of the purchasing behavior of IFWMP through AHP theory and analyzing the effect of these factors on the consumers' choice so as to offer reasonable comments and suggestions to guide investors on how to choose IFWMP scientifically.

\section{Methodology}

Analytic hierarchy process (AHP), which was originally developed by Saaty (1990), is a multi-criteria decision-making method ${ }^{[15,16]}$. AHP is used to solve unstructured decision-making problems that are subjective and non-quantifiable which are generally difficult to quantify or prioritize. One of the advantages of AHP is that numerical weight can be converted from intangible and non-quantifiable criteria by breaking down complicated decision-making affairs into simple hierarchy phases.

This method divides a complicated issue into a multi-layer structure consisting of the objective layer, index layer, and scheme layer as shown in Figure 1. In the decision-making criteria assessment, how to make decisions is generally regarded as the object layer while the assessment criteria are included in the index or even sub-index layers. In this work, the objective layer is "How to choose a satisfactory IFWMP," the index layer includes the potential influencing factors of purchasing IFWMP, and the scheme layer involves the common IFWMPs in the financial market.

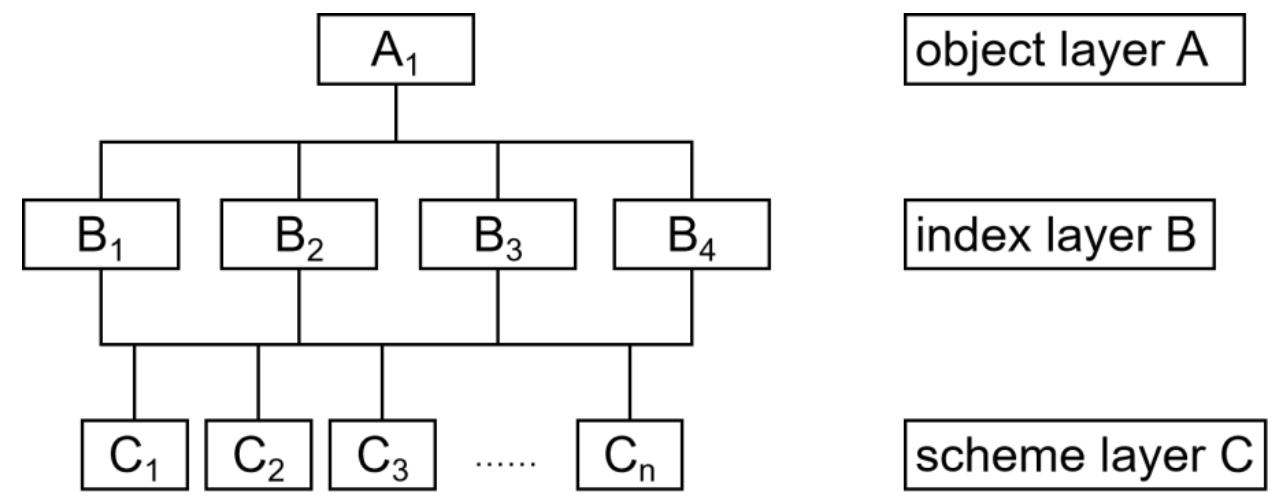

Figure 1. General structure of AHP

Generally, numbers ranging from 1 to 9 and their reciprocals are used to represent the relative importance of the assessment factors to risk in the constructed pairwise comparison ${ }^{[16]}$. In this work, the frequency analysis approach, which is used the most in market research, was adopted ${ }^{[17]}$. It expresses the degree of importance of each influential factor in the index layer by counting the numbers of selection times for each factor. In addition, the survey design is obviously much easier and more straightforward for survey subjects. Thus, it is possible for the surveyed to make their first intuitive selection which would reflect their real purchasing intention. 


\section{Survey design and results}

The survey was divided into two parts: personal information of interviewees and influencing factors of IFWMP selection. It was mainly carried out through typical internet platforms like Wechat, Weibo, etc. A total of 73 validated responses were received. The general background of the interviewees is shown in Table 1.

Table 1. Sample demographics

\begin{tabular}{|c|c|c|c|}
\hline Measure & Item & Frequency & Percentage $(\%)$ \\
\hline \multirow[t]{2}{*}{ Gender } & Male & 29 & $39.7 \%$ \\
\hline & Female & 44 & $60.3 \%$ \\
\hline \multirow[t]{5}{*}{ Age } & Under 18 & 1 & $1.4 \%$ \\
\hline & $18-24$ & 30 & $41.1 \%$ \\
\hline & $25-39$ & 20 & $27.4 \%$ \\
\hline & $40-50$ & 12 & $16.4 \%$ \\
\hline & Over 50 & 10 & $13.7 \%$ \\
\hline \multirow[t]{5}{*}{ Education level } & High school & 7 & $9.6 \%$ \\
\hline & College or university & 55 & $75.3 \%$ \\
\hline & Master & 9 & $12.3 \%$ \\
\hline & $\mathrm{PhD}$ & 1 & $1.4 \%$ \\
\hline & Others & 1 & $1.4 \%$ \\
\hline \multirow[t]{9}{*}{ Occupation } & $\begin{array}{l}\text { Leaders of government departments, enterprises, } \\
\text { and institutions, party and government organs, as } \\
\text { well as public organizations }\end{array}$ & 3 & $4.1 \%$ \\
\hline & $\begin{array}{l}\text { Professional and technical personnel (teachers, } \\
\text { doctors, engineers, writers, etc.) }\end{array}$ & 7 & $9.6 \%$ \\
\hline & Staff (for general service work) & 10 & $13.7 \%$ \\
\hline & Businessmen & 4 & $5.5 \%$ \\
\hline & Service personnel in the tertiary industry & 3 & $4.1 \%$ \\
\hline & Private entrepreneurs & 3 & $4.1 \%$ \\
\hline & Students & 32 & $43.8 \%$ \\
\hline & Retired or unemployed & 6 & $8.2 \%$ \\
\hline & Others & 5 & $6.8 \%$ \\
\hline \multirow{5}{*}{$\begin{array}{l}\text { Average disposable } \\
\text { income (pocket money or } \\
\text { living fees for students) }\end{array}$} & Under 1500 yuan & 18 & $24.7 \%$ \\
\hline & $1500-3000$ & 10 & $13.7 \%$ \\
\hline & $3000-5000$ & 18 & $24.7 \%$ \\
\hline & $5000-12000$ & 19 & $26.0 \%$ \\
\hline & Over 12000 & 8 & $11.0 \%$ \\
\hline \multirow[t]{5}{*}{ Risk tolerance } & Not below the expected returns & 6 & $8.2 \%$ \\
\hline & Not below the bank's interest rate & 17 & $23.3 \%$ \\
\hline & No loss of principal & 23 & $31.5 \%$ \\
\hline & Loss of principal not exceeding $10 \%$ & 18 & $24.7 \%$ \\
\hline & Loss of principal exceeding $10 \%$ & 9 & $12.3 \%$ \\
\hline
\end{tabular}


The relevant influencing factors were determined by combining and summarizing domestic as well as foreign literatures about IFWMP purchase as shown in Table 2, whose selection is based on the AHP analysis method and frequency analysis design as shown in Figure 2.

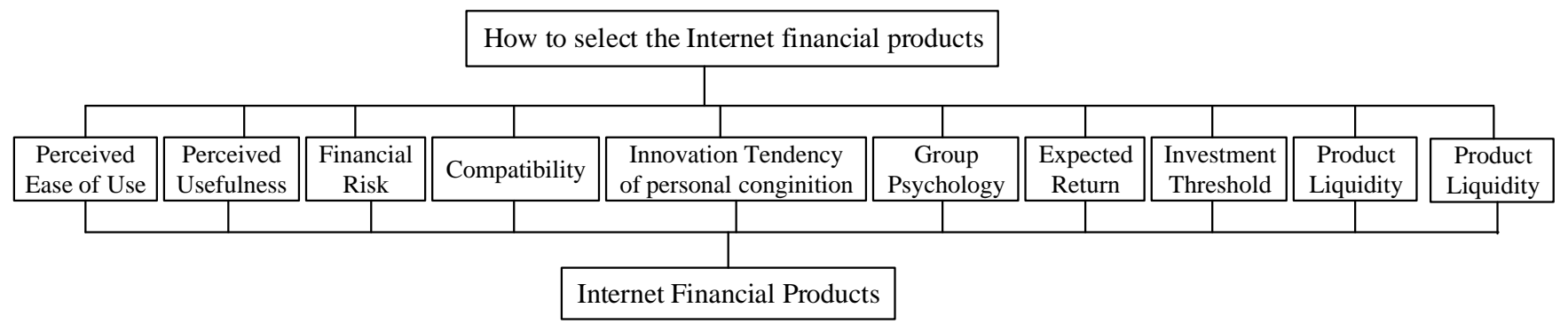

Figure 2. AHP of the influential factors of IFWMP purchase

Interviewees were required to select six to eight most important influential factors from ten factors. The importance of each factor was quantified by the frequency of factor selection. The equation of normalization is as follows:

$$
\text { Normalization }(\%)=\text { Frequency }(\%) / \text { Sum of frequency }(\%)
$$

Table 2. Definition and source of influential factors of IFWMP purchase

\begin{tabular}{l} 
Definition of factors \\
\hline Compatibility \\
Some IFWMPs that are adapted to an individuals' original \\
financial knowledge and experiences in purchasing financial \\
products or services, as well as to that individuals' current \\
consumption habits and financial needs.
\end{tabular}

\section{Perceived ease of use}

It is easy to access the IFWMP and can be quickly learned to operate.
Source

Moore and Benbasat (1991) in "Development of an

Instrument to Measure the Perceptions of Adopting an

Information Technology Innovation."

Moore and Benbasat (1991) in "Development of an

Instrument to Measure the Perceptions of Adopting an Information Technology Innovation."

David in "A Technology Acceptance Model for Empirically

Testing New End-User Information Systems: Theory and Results."

\section{Perceived usefulness}

IFWMP is able to help manage wealth efficiently.

Moore and Benbasa (1991) in "Development of an Instrument to Measure the Perceptions of Adopting an Information Technology Innovation."

David in "A Technology Acceptance Model for Empirically Testing New End-User Information Systems: Theory and Results."

\section{Financial risk}

Likely to lose the principal when purchasing an IFWMP, which may happen because of investment risks and corporate moral hazard.
Mo Zichang (2018) in "Research on Influencing Factors of

Consumers' Purchase of Internet Financial Products."

Zhao, Xue, and Li (2017) ${ }^{[11]}$. 


\section{Privacy risk}

Likely to face the risks of private information being stolen or leaked.

\section{Innovation tendency of personal cognition}

Purchase (or desire to buy) because of the curiosity toward IFWMP.
Wang Chi (2019) in "An Investigation Report on Influencing Factors of Harbin University Students' Willingness to Purchase Internet Financial Products: The Case of Yu'ebao." Zhao, Xue, and Li (2017) ${ }^{[10]}$.

Rong-An Shang and Yu-Chen Chen (2005) in "Extrinsic

Versus Intrinsic Motivations for Consumers to Shop OnLine." relatives, or the popular rather than what is chosen in the Zhao, Xue, and Li (2017) ${ }^{[11]}$.

\section{Expected return} Zhao, Xue, and Li (2017) ${ }^{[11]}$.

Prefer certain IFWMP with high returns and low risks.

Investment threshold
Prefer IFWMP since it has low threshold and improves the

idle capital utilization.

Product liquidity $\quad$ Wang (2016) ${ }^{[6]}$.

Prefer the financial way that enables the withdrawal of cash at any time.

Based on the collected samples, it is shown that the respondents with age ranging from 18 to 24 years old accounted for $41.1 \%$, and the respondents with age ranging from 25 to 39 years old accounted for $27.4 \%$. The figure from China Business Network data center (CBNData) and Ant Fortune, which jointly released Who is the Biggest Winner: 2019 Online Wealth Management Crowd Report, demonstrated that the majority of internet wealth management users consisted of the post-80s and post-90s generation (33\% and $30 \%$, respectively). These people used more internet resources and over $60 \%$ of them purchased wealth management product through online for the first time ${ }^{[18]}$. These youngsters are open-minded and have an innovative spirit where they are willing to actively embrace change and accept all kinds of novel things. Compared with the people from the old times, it is more possible for them to accept internet financial products. Therefore, the selection of samples was well-targeted.

Based on the above report, it was found that the people in the age group of 20-30 years old generally had lower-risk tolerance. The proportion of people in the age groups of 20-25 and 25-30 years old that "cannot accept loss" (44\% and 39\%, respectively) and "can only accept loss within 5\% of the principal" (10\% and $12 \%$, respectively) were higher than those of other age groups ${ }^{[18]}$. These people have limited funds for investment, so they are more satisfied with IFWMPs which have low investment threshold and great liquidity that enables people to withdraw their funds anytime and anywhere.

It can also be seen that in the occupation distribution, the percentage of students accounted for $43.8 \%$, which might have caused the tendency of the general analysis to present students' purchase preferences. However, the sample analysis showed that the proportion of respondents with monthly disposable income of below 3000 yuan and who could accept a rate higher than the bank's interest rate were $38.4 \%$ and $31.5 \%$, respectively. Therefore, students' characteristics in term of low disposable income and poor risk tolerance were not quite obvious in the general analysis of sample demographics.

Additionally, most of the interviewees had received or were receiving higher education (89\%). In general, the mass with higher education level had a higher acceptance and understanding of new things as well as the ability to master the internet better. IFWMP has been formed and developed in recent decades and the samples mainly consisted of people with higher education level, hence it can be assured to some 
extent in terms of its validity and stability.

Table 3. Relative frequency and normalization of influential factors of IFWMP purchase

\begin{tabular}{|c|c|c|}
\hline Factors & Relative frequency & Normalization \\
\hline Compatibility & $80.82 \%$ & $12.66 \%$ \\
\hline Perceived ease of use & $75.34 \%$ & $11.80 \%$ \\
\hline Perceived usefulness & $78.08 \%$ & $12.23 \%$ \\
\hline Financial risk & $58.90 \%$ & $9.23 \%$ \\
\hline Privacy risk & $61.64 \%$ & $9.66 \%$ \\
\hline Innovation tendency of personal cognition & $31.51 \%$ & $4.94 \%$ \\
\hline Group psychology & $39.73 \%$ & $6.22 \%$ \\
\hline Expected return & $61.64 \%$ & $9.66 \%$ \\
\hline Investment threshold & $71.23 \%$ & $11.16 \%$ \\
\hline Product liquidity & $79.45 \%$ & $12.45 \%$ \\
\hline
\end{tabular}

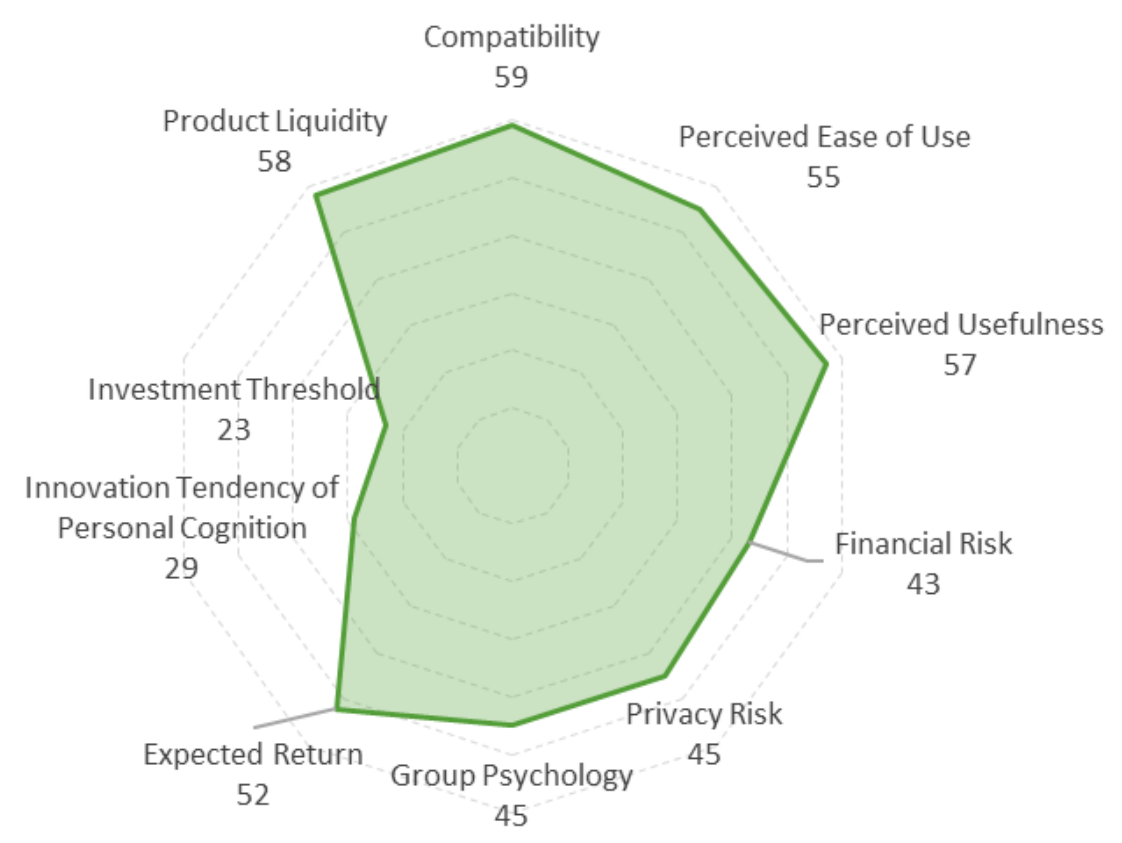

Figure 3. Selection frequency of influential factors of IFWMP purchase

From Figure 3, among the ten given factors, the selection frequency of compatibility was the highest (80.8\%); accounting for $12.6 \%$ in terms of the significance of all ten factors. Compatibility means that people combined their financial experiences and current financial demands when purchasing IFWMPs. As shown in Table 3, the next popular ones were product liquidity, perceived usefulness, and perceived ease of use, which accounted for $79.5 \%, 78.1 \%$, and $75.3 \%$, respectively. Personal cognition had the least significant impact (4.94\%) with only $31.5 \%$ respondents believing they would be affected in choosing the IFWMPs (Table 3). 
Table 4. Cross analysis of age and influential factors of IFWMP purchase

\begin{tabular}{lccccc}
\hline Factors & Under 18 & $18-24$ & $25-39$ & $40-50$ & Over 50 \\
\hline Perceived ease of use & 1 & 23 & 16 & 10 & 5 \\
Perceived usefulness & 0 & 25 & 14 & 9 & 9 \\
Financial risk & 1 & 20 & 9 & 5 & 8 \\
Privacy risk & 1 & 21 & 11 & 8 & 4 \\
Innovation tendency of personal cognition & 0 & 6 & 8 & 3 & 6 \\
Compatibility & 0 & 23 & 18 & 9 & 9 \\
Group psychology & 1 & 8 & 10 & 3 & 7 \\
Expected return & 1 & 19 & 10 & 9 & 6 \\
Investment threshold & 1 & 23 & 13 & 6 & 9 \\
Product liquidity & 0 & 22 & 18 & 10 & 8 \\
Sum & 1 & 30 & 20 & 12 & 10 \\
\hline
\end{tabular}

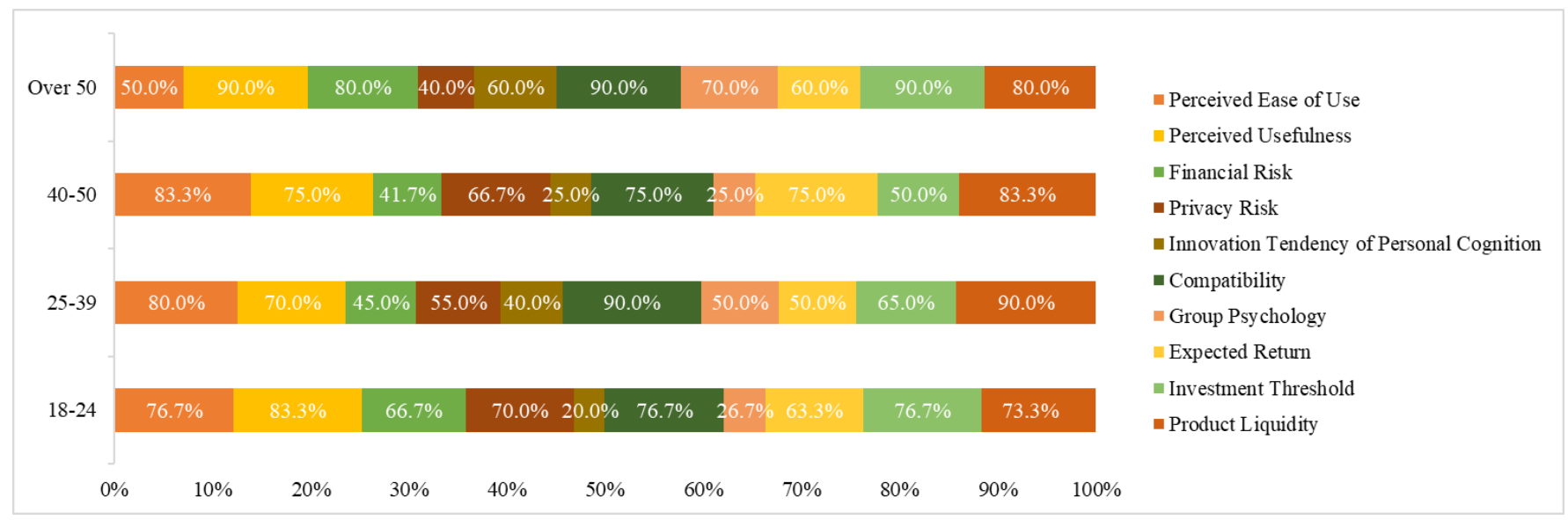

Figure 4. Cross analysis of age and influential factors of IFWMP purchase

According to the cross analysis of age and influential factors of IFWMP purchase in Table 4, the mass of all ages mainly focused on four characteristics: compatibility, perceived usefulness, perceived ease of use, and product liquidity except that people over 50 years old paid relatively less attention to perceived ease of use. The different age groups attached different importance to these factors. For instance, the youngsters paid more attention to whether the IFWMPs could effectively manage their wealth while people in the age group of 25-39 years old focused more on observing compatibility and the liquidity of the products while they focused less on the financial risks and privacy risks compared to the elderly. People in the age group of 40-50 years old were more concerned about the perceived ease of use and the product liquidity in addition that they paid more attention to the expected return of IFWMPs compared to other age groups, whereas those above 50 years old were most influenced by compatibility, perceived usefulness, and financial thresholds. In addition, the oldest age group was affected by innovation tendency of personal cognition and group psychology, but lower importance was placed for privacy risks (Figure 4). Due to the limited samples of under 18 respondents, the characteristics for these group of people were not expressed in this work. 
Table 5. Cross analysis of gender and influential factors of IFWMP purchase

\begin{tabular}{lcc}
\hline \multicolumn{1}{c}{$\mathrm{X} \backslash \mathrm{Y}$} & Male & Female \\
\hline Compatibility & 24 & 35 \\
Perceived ease of use & 22 & 33 \\
Perceived usefulness & 24 & 33 \\
Financial risk & 17 & 26 \\
Privacy risk & 18 & 27 \\
Innovation tendency of personal cognition & 11 & 12 \\
Group psychology & 15 & 14 \\
Expected return & 16 & 29 \\
Investment threshold & 18 & 34 \\
Product liquidity & 21 & 37 \\
Sum & 29 & 44 \\
\hline
\end{tabular}

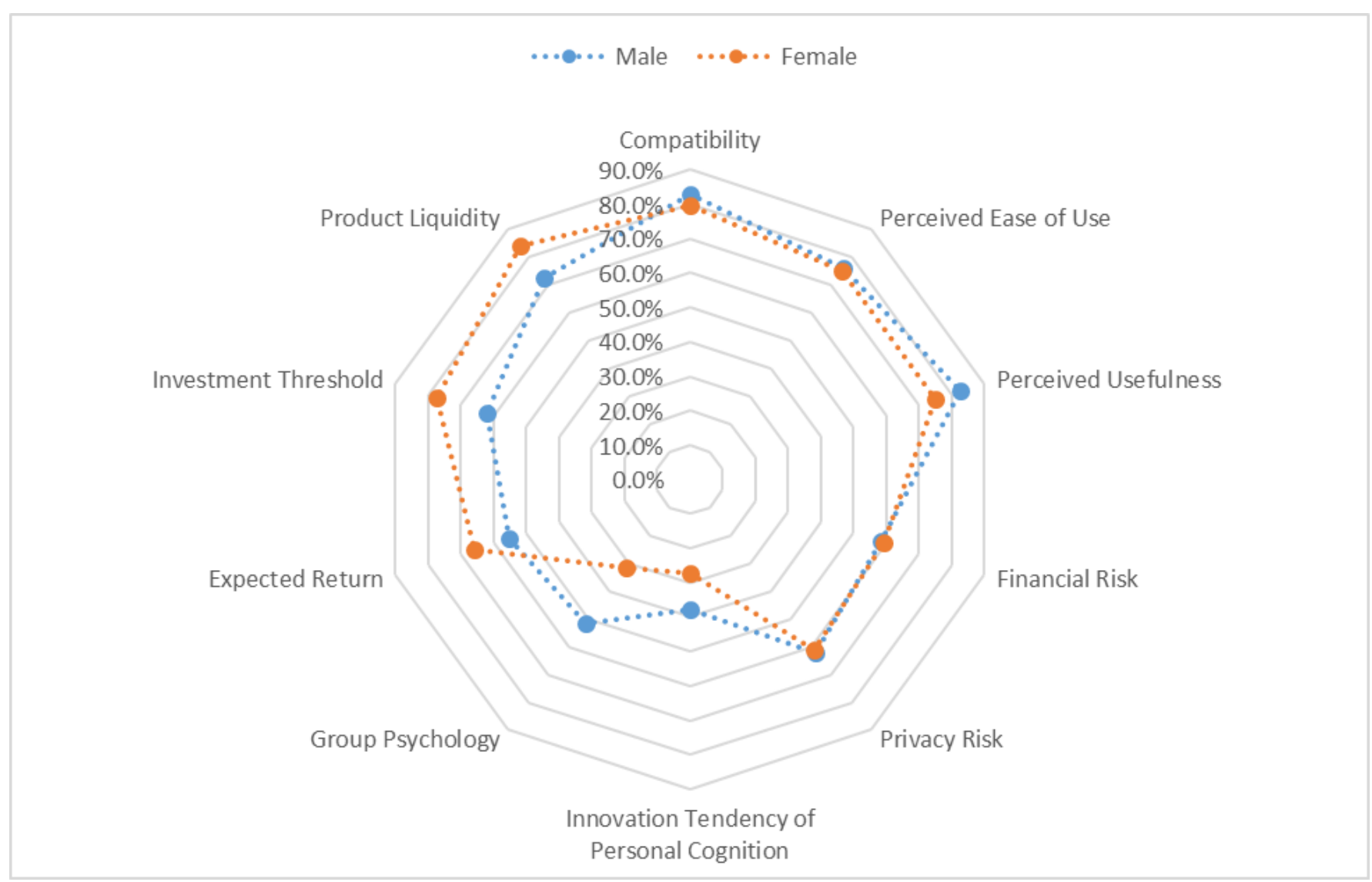

Figure 5. Cross analysis of gender and influential factors of IFWMP purchase

The prominent differences in the preference of purchasing IFWMP by gender were group psychology, investment threshold, and product liquidity. Group psychology reflected the largest gender preference distinction, which had greater impact on male. On the contrary, women were more affected by investment threshold and product liquidity (Table 5 and Figure 5). 
Table 6. Cross analysis of risk tolerance and influential factors of IFWMP purchase

\begin{tabular}{lccccc}
\hline \multicolumn{1}{c}{$\mathrm{X} \backslash \mathrm{Y}$} & $\begin{array}{c}\text { Not below the } \\
\text { expected returns }\end{array}$ & $\begin{array}{c}\text { Not below the } \\
\text { bank's interest rate }\end{array}$ & $\begin{array}{c}\text { No loss of } \\
\text { principal }\end{array}$ & $\begin{array}{c}\text { Loss of principal } \\
\text { not exceeding 10\% }\end{array}$ & $\begin{array}{c}\text { Loss of principal } \\
\text { exceeding 10\% }\end{array}$ \\
\hline Perceived ease of use & 4 & 14 & 15 & 14 & 8 \\
Perceived usefulness & 6 & 13 & 17 & 13 & 8 \\
Financial risk & 6 & 13 & 8 & 11 & 5 \\
Privacy risk & 6 & 11 & 12 & 10 & 6 \\
Innovation tendency of & 2 & 4 & 5 & 7 & 5 \\
personal cognition & & & & & \\
Compatibility & 5 & 14 & 21 & 11 & 5 \\
Group psychology & 2 & 4 & 6 & 12 & 4 \\
Expected return & 2 & 11 & 14 & 14 & 5 \\
Investment threshold & 1 & 12 & 20 & 14 & 5 \\
Product liquidity & 4 & 13 & 20 & 16 & 9 \\
Sum & 6 & 17 & 23 & 18 & 5 \\
\hline
\end{tabular}

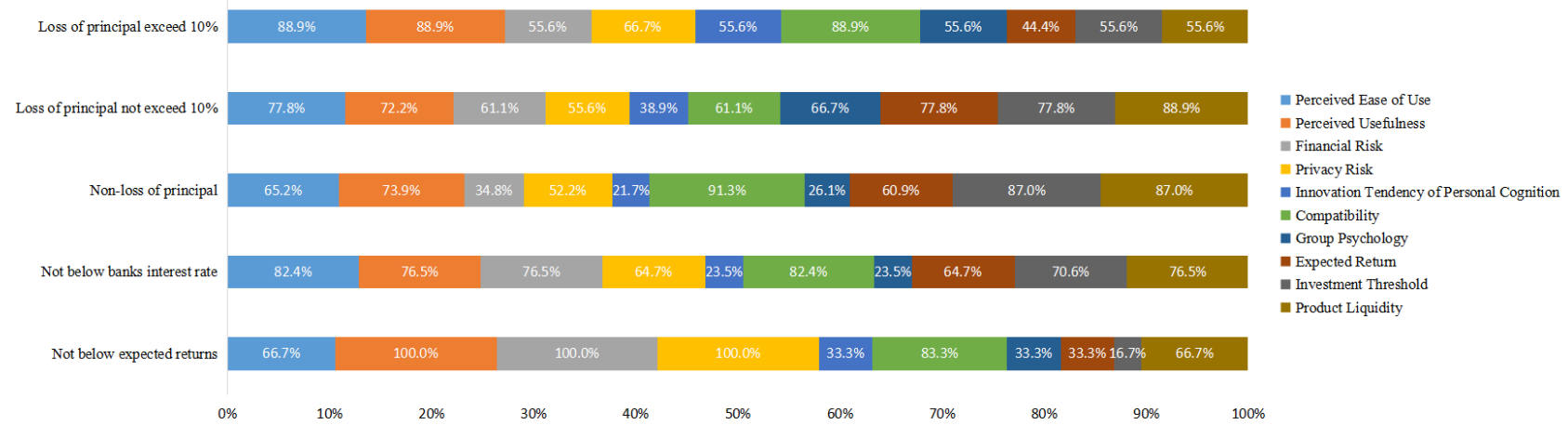

Figure 6. Cross analysis of risk tolerance and influential factors of IFWMP purchase

Through cross-analysis of risk tolerance and the influential factors as shown in Table 6 and Figure 6, it was found that risk-loving investors in the sample were more likely affected by innovation tendency of personal cognition and group psychology while risk-neutral investors kept eyes on compatibility, investment threshold, and product liquidity. In contrast, risk-averse investors paid more attention to perceived usefulness, financial risk, and privacy risk of IFWMPs.

\section{Analysis and discussion}

Based on the above analysis, it can be obviously appreciated that for financial investors, compatibility is a key factor to be considered when choosing IFWMPs. Moreover, compatibility was not affected by choice preferences regardless of age and gender so investors should give priority to whether the IFWMP matches his or her own financial concepts and consumer needs.

Product liquidity should be the second consideration for most people. Compared with the traditional financial wealth management products, IFWMPs apparently have great advantages in liquidity in which they become the reason why most people choose to buy them. This factor is important to young people who have graduated because they are no longer campus students without too much consumption needs and desires, and they have to financially support themselves or even their families. They would be more pursuing in regard to whether their funds of certain financial products can be withdrawn immediately where 
women should give more priority to product liquidity.

For perceived ease of use and perceived usefulness, basically people of all ages should also pay attention to these two factors. However, it can be seen from the sample analysis that people over 50 years old did not pay much attention to the ease of conducting purchase and the operation of financial management products compared to other age groups. It can be speculated that some of them might be accustomed to the traditional financial management tools and the operation process, so the perceived ease of use did not affect their choices whereas they paid more attention to other characteristics of the emerging financial management tools, such as perceived usefulness and financial threshold. Perceived usefulness is one of the factors that have relatively stable importance which is not affected by age, gender, and risk tolerance preferences. Investors should consider whether an IFWMP can improve their financial efficiency after considering the above relevant factors.

Financial management threshold should be an important influencing factor to certain people. For instance, for women and risk-neutral people, the product that lowers its own financial management threshold to improve the financial management efficiency of investors' idle funds should become one of the most important factors to consider while purchasing IFWMP.

Privacy risks and financial risks did not affect the general investor's choice. However, risk-averse people should give priority to the influence of financial risks in the purchase of IFWMP. Older people and students should also consider the financial risks which can result from the purchase of financial products. Among all age groups, young people, especially students, should pay attention to the privacy risks stemmed from the purchasing IFWMP to observe whether purchasing the product would reveal their personal information and other important private data.

The expected return factor was highly valued among female investors and risk-neutral investors. For investors who can bear certain risks, the expected return rate of the product would become an important factor of concern.

Innovation tendency of personal cognition and group psychology had limited impact on general public investors. However, for people that were over 50 years old in the sample, these two factors were given more attention. Elderly investors should rationally think about whether the recommendations of others have a certain degree of credibility when they choose to buy IFWMPs and whether they have a high degree of awareness for curiosity about emerging products. Additionally, male investors and risk-enthusiasts were also more affected by these two factors, hence they also need to think about the above issues before making a purchase.

\section{Conclusion}

The research on influential factors of purchasing IFWMPs was conducted based on AHP and the investigation results. The survey incorporated ten popular and relevant factors to provide a more comprehensive investigation. The results showed that compatibility, product liquidity, perceived ease of use, and perceived usefulness were the most important factors, which people considered before buying IFWMPs.

\section{Disclosure statement}

The author declares that there is no conflict of interest.

\section{References}

[1] National Bureau of Statistics, 2020, National Annual Data. https://data.stats.gov.cn (accessed on November 21, 2020). 
[2] China Merchants Bank, 2020, China Merchants Bank and Bain \& Company jointly release the "2019 China Private Wealth Report”. http://www.cmbchina.com/privatebank/PrivateBankInfo.aspx?guid=bd eb435b-cc83-4b54-b92a-7eab597ecbf7 (accessed on November 21, 2020).

[3] 2020, People's Bank of China and Other 10 Government Departments Issued Guidance on Promoting the Healthy Development of Internet Finance. http://www.gov.cn/xinwen/2015-07/18/content_289936 0.htm (accessed on December 4, 2020).

[4] Tianhong Fund Management Co. Ltd., 2020, Tianhong Yu'e Bao Money Market Fund Annual Report 2019, 5-7, 54. http://pdf.dfcfw.com/pdf/H2_AN202004241378540578_1.pdf

[5] Xia X, Du Z, 2014, Research on Influencing Factors of Consumers' Purchase of Internet Financial Products. Money China, (20): 55, 201. https://kns.cnki.net/kcms/detail/detail.aspx?FileName=CJJI2 $01420042 \&$ DbName $=$ CJFQ2014

[6] Wang R, 2016, Analysis on the Influencing Factors of the Purchase Decision of Internet Financial Products. Communication of Finance and Accounting, (29): 3-5, 129. doi: 10.16144/j.cnki.issn10028072.2016.29.001

[7] Qiu J, Yang Q, Guo L, 2015, On the Influencing Factors of Internet Financial Products' Usage. Journal of Intelligence, (01): 179-84.

[8] Martins C, Oliveira T, Popovič A, 2014, Understanding the Internet Banking Adoption: A Unified Theory Of Acceptance and Use of Technology and Perceived Risk Application. International Journal of Information Management, 34(1): 1-13. doi: 10.1016/j.ijinfomgt.2013.06.002

[9] Liu Y, Wang B, Ma X, 2015, An Empirical Study on Internet Financial Product Purchase Intention Based on RBF Neural Network. Shanghai Management Science, (01): 10-3.

[10] Zhao Q, Xue J, Li Y, 2017, Research on Influencing Factors of Internet Financial Product Consumption based on Diffusion of Innovation. Finance Economy, (01): 168-70.

[11] Zhao Q, Xue J, Li Y, 2017, Research on the Choice of Internet Financial Products Based on Nested Logit Model. Science and Management, 37(05): 38-47. doi: 10.3969/j.issn.1003-8256.2017.05.006

[12] Xu X, Lu M, 2017, Research on the Behavior of Online Financial Wealth Product Purchasing Based on Social Cognitive Theory. Soft Science, 31(05): 108-13. doi: 10.13956/j.ss.1001-8409.2017.05.24

[13] Zhang H, Liao H, Wu X, et al., 2020, Internet Financial Investment Product Selection with Pythagorean Fuzzy DNMA Method. Inzinerine Ekonomika-Engineering Economics, 31(01): 61-71. doi: https://doi.org/10.5755/j01.ee.31.1.23255

[14] Arif I, Aslam W, Hwang Y, 2020, Barriers in Adoption of Internet Banking: A Structural Equation Modeling - Neural Network Approach. Technology in Society, 61. doi: 10.1016/j.techsoc.2020.101231

[15] Saaty TL, 1990, How to Make a Decision: The Analytic Hierarchy Process. European Journal of Operational Research, 48(01): 9-26. https://doi.org/10.1016/0377-2217(90)90057-I

[16] Lyu H, Zhou W, Shen S, et al., 2020, Inundation Risk Assessment of Metro System Using AHP and TFN-AHP in Shenzhen. Sustainable Cities and Society, 56.

[17] Wu S, 2005, The Application of SPSS in Market Research. China Science and Technology Information, (18): 254-9.

[18] 2019, 2019 Online Wealth Management Crowd Report. http://www.199it.com/archives/842794.html (accessed on January 15, 2021). 